\title{
Does travel broaden the scientific mind?
}

\author{
Rosemary Clyne: \\ Learn about the customs \\ of your host country and \\ if a foreign language is \\ spoken, learn as much as \\ you can prior to arrival.
}

W hen it comes to young scientific talent, there is a trade deficit between the United States and the rest of the world. Every year, hundreds of foreign-born postdocs take up positions in the United States, whereas only a fraction of that number of US-born scientists take up similar positions abroad.

Why the imbalance? Many US graduates fear that a stint abroad will jeopardize their chances at home by taking them out of the US science networking loop. But a growing minority believe that the experience broadens their horizons and increases their employment opportunities.

"I decided to go abroad for both professional and personal reasons," says Daniel Zucker, an astronomer at the Max Planck Institute in Heidelberg. He hasn't regretted the decision. Zucker, who studies the histories of nearby galaxies, says that the chance to do good science while experiencing another culture and learning another language attracted him to the US National Science Foundation's International Research Fellowship Program, which funds his Heidelberg post.

\section{JOB-HUNTING FROM A DISTANCE}

E-mail and the Internet may have ended the perception that working overseas leaves postdocs out of touch. But do stay in contact with former collaborators and advisers, warns Bianca Sclavi, a postdoctoral researcher at the Laboratory for Biotechnology and Applied Pharmacology at the Ecole Normale Supérieure de Cachan in Paris. "It's a good idea to go back for meetings to keep in touch, at least once a year," she says.

"The main disadvantage of working abroad is that I feel a bit out of the American job-search loop," says Darren Irwin, a guest researcher at the Molecular Population Biology Laboratory at Lund University in Sweden. "Travelling from Sweden to visit American universities is both time-consuming and expensive."

But this is a temporary disadvantage, says Irwin. Once back in the United States he suspects that his international experience will strengthen his chances of gaining a professorship. "It can be an excellent learning experience to see how scientists in other countries do their work and what subjects they are interested in," he says. "I feel that my knowledge has broadened

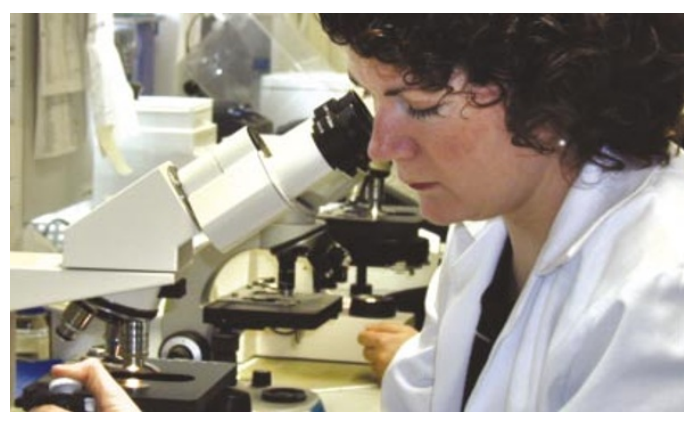

substantially as a result of working in both countries."

Psychologist Casey Cromwell did a postdoc at the University of Fribourg's Institute of Physiology in Switzerland from 1996 to 2000. After that he worked at Wake Forest University Medical School in WinstonSalem, North Carolina, before taking his current post at Bowling Green State University in Ohio. Cromwell says he never really felt out of the loop while abroad. "I was brought over to do a few interviews while I was still in Switzerland," he says. "I got telephone interviews from the States." The web and e-mail made it easy to find a job, he says, although he admits to being a bit worried before he landed the Wake Forest position.

\section{PLUSES AND MINUSES}

Making the move to another culture and language can seem daunting. But many of the people postdocs encounter, especially scientists, speak excellent-tofunctional English. Postdocs often take a language course, sometimes paid for by their host lab. The main difficulties in adjusting have to do with the details of day-to-day life such as shopping for food, setting up a bank account and renting somewhere to live, all of which are done differently and in some cases take much longer than in the United States.

Rosemary Clyne, a postdoctoral fellow at Austria's Research Institute of Molecular Pathology in Vienna, counsels postdocs to be flexible and open-minded. "Austria's not the land of convenience that the United States is, but in my opinion this is part of its character," she says. But the trade-offs are worth it. "The quality of the institute's science and facilities far outweigh minor inconveniences like being unable to shop on Sunday," says Clyne. And Vienna has much to offer. "The cultural opportunities here rival any US city and a postdoc can afford to enjoy them," adds Clyne, who studies meiosis in the yeast Saccharomyces cerevisiae.

Her advice is to research the lab, institute and city as extensively as possible. "Choose a lab that is wellrecognized and whose group leader has broad contacts. Learn about the customs of your host country and if a foreign language is spoken, learn as much as you can prior to arrival." And, she adds, be prepared for numerous visits from envious friends and relatives. Karen Kreeger is a freelance science writer based in Philadelphia.
Web links Research Institute of Molecular Pathology www.imp.univie.ac.at NSF International Research Fellowship Program t www.nsf.gov/cgi-bin/ getpub?nsf002149 